\title{
Sonolysis of Carbon Dioxide, Nitrous Oxide and Methane in Aqueous Solution
}

\author{
A. Henglein \\ Hahn-Meitner-Institut für Kernforschung Berlin, D-1000 Berlin 39 \\ Herrn Professor Dr. Dietrich Schulte-Frohlinde zum 60. Geburtstag gewidmet \\ Z. Naturforsch. 40b, 100-107 (1985); received August 14, 1984. \\ Ultrasonic Waves, Carbon Dioxide, Nitrous Oxide, Methane, Free Radicals
}

Water was irradiated with ultrasonic waves under an argon atmosphere which contained small amounts of carbon dioxide, nitrous oxide or methane. The yield of the products was measured as a function of the composition of the gas atmosphere. Maximum yields were observed at a few per cent of the added polyatomic gas. No chemical effects occurred in the irradiation under an atmosphere of pure $\mathrm{CO}_{2}, \mathrm{~N}_{2} \mathrm{O}$ or $\mathrm{CH}_{4}$. It is concluded that the gas mixture in the tiny gas bubbles, in which the chemical effects are brought about, is not in Henry's equilibrium with the aqueous gas solution.

The main product of the sonolysis of $\mathrm{CO}_{2}$ is $\mathrm{CO}$, a small amount of formic acid also being formed. The sonolysis is explained by both the attack of $\mathrm{H}$ atoms from the sonolysis of water and direct decomposition of $\mathrm{CO}_{2}$ due to the high temperatures existing in compressed gas bubbles. The main products of the sonolysis of $\mathrm{N}_{2} \mathrm{O}$ are nitrogen, nitrite and nitrate. $\mathrm{N}_{2} \mathrm{O}$ enhances the rate of various oxidations such as that of iodide, nitrite and propanol-2. In the methane containing solution, a lot of hydrogen is produced, the main oxidation products being ethane, ethylene, $\mathrm{C}_{3^{-}}$ and $\mathrm{C}_{4}$-hydrocarbons and carbon monoxide. A mechanism is postulated which involves both the attack on methane by radicals from the decomposition of water and thermal decomposition of methane. The local radical concentrations are so high that a methane molecule may undergo multiple radical attack. The similarity between sonolytic reactions and reactions occurring in flames is emphasized.

\section{Introduction}

Although it has been known for several decades that ultrasonic waves initiate redox reactions in aqueous solutions $[1,2]$, such as the formation of hydrogen peroxide and the oxidation of iodide, the mechanism of these reactions is not understood in detail. The chemical effects are brought about only in the presence of a monoatomic or diatomic gas. The cavitation caused by the ultrasound produces small gas bubbles. It is believed that the chemical reactions are initiated by the high temperatures of several $1000 \mathrm{~K}$ and pressures of about 100 bar which exist for a short time during the adiabatic compression phase of oscillating [3] or collapsing [4, 5] gas bubbles. The monoatomic and diatomic gases have rather low specific heats, i.e. the rise in temperature is especially high in bubbles of these gases. Sonolysis of aqueous solutions is accompanied by luminescence $[6,7]$. Free radicals often are the intermediates of the chemical reactions. They have been traced via the polymerization of dissolved acrylamide [8] and, more recently, via a spin trapping method [9]. It has even been suspected that $\mathrm{H}$ and $\mathrm{OH}$ radicals are formed under diagnostic irradiation conditions [10].

$0340-5087 / 85 / 0100-0100 / \$ 01.00 / 0$
Chemical effects do not occur when aqueous solutions are irradiated under an atmosphere of carbon dioxide, nitrous oxide or methane. However, these gases undergo effective sonolysis when they are present at low concentrations in an argon atmosphere, under which the sonication of water is carried out. The following questions are dealt with: 1) Is the added polyatomic gas decomposed directly? 2) Is it decomposed indirectly as free radicals from the sonolysis of water attack it? 3) How do the chemical yields depend on the composition of the gas mixture? With respect to the latter question it is important to discuss the possibility that the chemically active gas bubbles are not in Henry's equilibrium with the liquid gas solution.

\section{Experimental}

The irradiations were carried out with a $300 \mathrm{kHz}$ quartz oscillator, the high frequency power delivered to it being $3.5 \mathrm{watt} / \mathrm{cm}^{2}$. The waves passed through a cooled water bath into a thin glass vessel containing $20 \mathrm{~cm}^{3}$ of the solution. The position of the vessel in the water bath could be adjusted to reach maximum power uptake from the ultrasonic field [11]. The bulk solution temperature during sonication was not higher than $20^{\circ} \mathrm{C}$.

Gases were determined with a gas chromatograph, organic acids with an ion chromatograph, iodine 
spectrophotometrically $\left(2.6 \times 10^{4} \mathrm{M}^{-1} \mathrm{~cm}^{-1}\right.$ at $350 \mathrm{~nm}$ in $0.1 \mathrm{M} \mathrm{KI}$ solution), and hydrogen peroxide spectrophotometrically after addition of titanyl sulfate $\left(620 \mathrm{M}^{-1} \mathrm{~cm}^{-1}\right.$ at $\left.400 \mathrm{~nm}\right)$. Aldehydes were determined as 2,4-dinitrophenyl hydrazones using high pressure liquid chromatography [12].

The solutions were strongly bubbled with the desired gas mixture for 20 minutes before sonication. During the irradiation, the vessel was closed. Its total volume was $135 \mathrm{~cm}^{3}$. The vessel carried a septum through which samples of the gas atmosphere could be taken off for analysis.

\section{Results}

\section{Sonolysis of solutions containing $\mathrm{CO}_{2}$.}

The main products of sonolysis of water under pure argon are hydrogen and hydrogen peroxide which are formed in practically equimolar amounts (Fig. 1). Upon the addition of $\mathrm{CO}_{2}$ to the argon atmosphere, the hydrogen yield is decreased. In order to decrease this yield by a factor of two, only $0.5 \%$ of $\mathrm{CO}_{2}$ was required. On the other hand, the yield of hydrogen peroxide increased and substantial amounts of $\mathrm{CO}$ were observed. Oxygen was formed in the sonolysis of water under pure argon only to a very small extent. An increase in $\mathrm{O}_{2}$ formation was observed in the presence of small amounts of $\mathrm{CO}_{2}$.

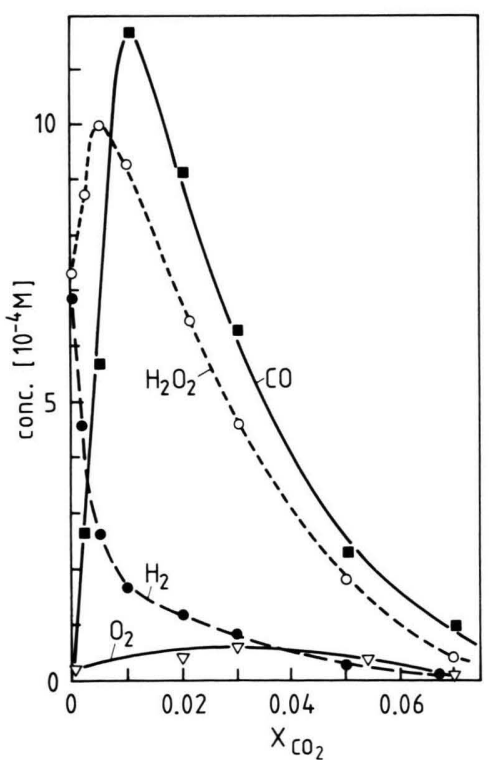

Fig. 1. Yields of various products in the irradiation of water under an $\mathrm{Ar}-\mathrm{CO}_{2}$ atmosphere as function of the $\mathrm{CO}_{2}$ mole fraction. Sonication time: $15 \mathrm{~min}$.
At mole fractions of $\mathrm{CO}_{2}$ greater than 0.03 all yields decreased as may also be seen from Fig. 1. It is interesting to note that the maxima in the yield $v s$. concentration curves appear at different $\mathrm{CO}_{2}$ concentrations for $\mathrm{H}_{2} \mathrm{O}_{2}, \mathrm{CO}$, and $\mathrm{O}_{2}$.

Formic acid was also found as a product of sonolysis of $\mathrm{CO}_{2}$. Its yield was about 30 times smaller than the $\mathrm{CO}$ yield.

Experiments were also carried out with an argonhydrogen (4:1) mixture to which $2 \%$ of $\mathrm{CO}_{2}$ was added. The yield of $\mathrm{CO}$ was twice as great as in the absence of hydrogen, while the yield of formic acid increased by a factor of five.

The systems mentioned so far contained only gaseous solutes. Experiments were also carried out with aqueous solutions of iodide and of ethanol, i.e. solutes which do not readily evaporate into the gas bubbles. Fig. 2 shows the yield of iodine in a sonicated iodide solution at various compositions of the argoncarbon dioxide atmosphere. It is seen that $\mathrm{CO}_{2} \mathrm{ex}-$ erts an increasingly inhibiting effect as its concentration becomes greater. In solutions containing ethanol and $\mathrm{CO}_{2}$, formic acid, acetic acid and lactic acid appeared as products. Fig. 3 shows the yields as functions of the mole fraction of $\mathrm{CO}_{2}$ in the argon- $\mathrm{CO}_{2}$ gas mixture. Curves with maxima were obtained as in Fig. 1. The organic acids were cross-combination products from the sonolyses of ethanol and $\mathrm{CO}_{2}$. However, they were only by-products. The main products were formaldehyde and acetaldehyde, their yields being about five times larger than the yields of the acids. The aldehyde yield was about constant up to a $\mathrm{CO}_{2}$ mole fraction of 0.03 and decreased at larger $\mathrm{CO}_{2}$ concentrations, as shown by Fig. 4 .

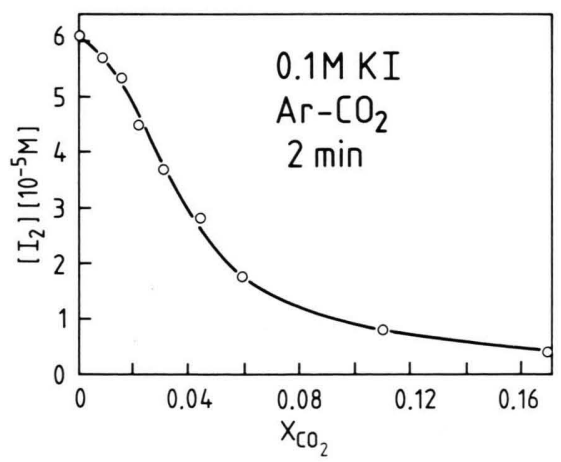

Fig. 2. Sonication of a $0.1 \mathrm{M}$ KI solution under argon. Iodine yield as a function of the mole fraction of $\mathrm{CO}_{2}$ added to the argon. 


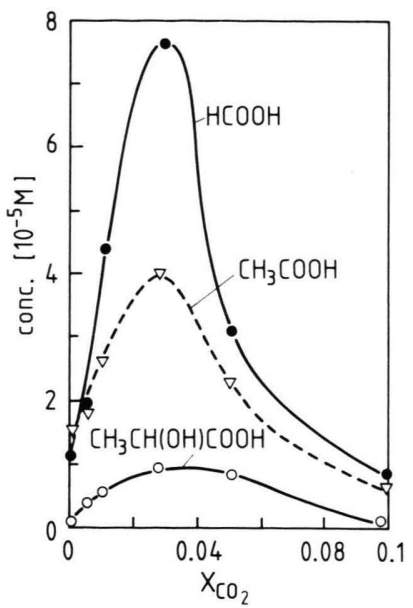

Fig. 3. Sonication of $0.05 \mathrm{M}$ ethanol solution under an $\mathrm{Ar}-\mathrm{CO}_{2}$ atmosphere. Yields of organic acids as function of the $\mathrm{CO}_{2}$ mole fraction.

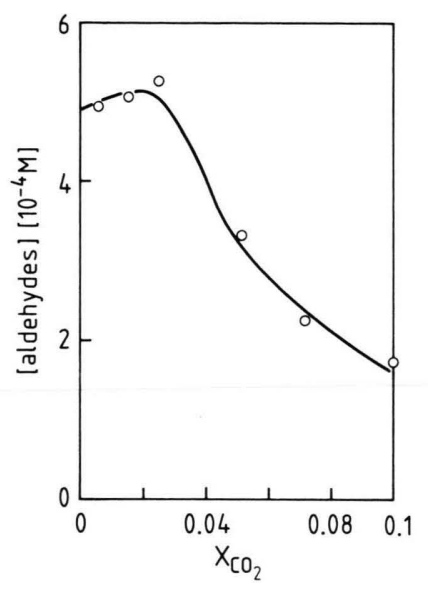

Fig. 4. Yield of aldehydes (formaldehyde plus acetaldehyde) in the irradiation of $0.05 \mathrm{M}$ ethanol solution under an $\mathrm{Ar}-\mathrm{CO}_{2}$ atmosphere. Concentration as a function of the mole fraction of $\mathrm{CO}_{2}$.

\section{Sonolysis of solutions containing $\mathrm{N}_{2} \mathrm{O}$}

Fig. 5 shows how the rate of iodine formation in a $0.1 \mathrm{M}$ KI solution depends on the mole fraction of $\mathrm{N}_{2} \mathrm{O}$ in the argon-nitrous oxide atmosphere. Maximum rate is observed at $\mathrm{X}_{\mathrm{N}_{2} \mathrm{O}}=0.04$, the rate being here about ten times greater than in the absence of $\mathrm{N}_{2} \mathrm{O}$. It is clear from this observation that $\mathrm{N}_{2} \mathrm{O}$ at low concentrations exerts a strong promoting effect on the oxidation of iodide. Nitrogen was found as a gaseous reaction product, its yield being $30 \%$ lower than the iodine yield.

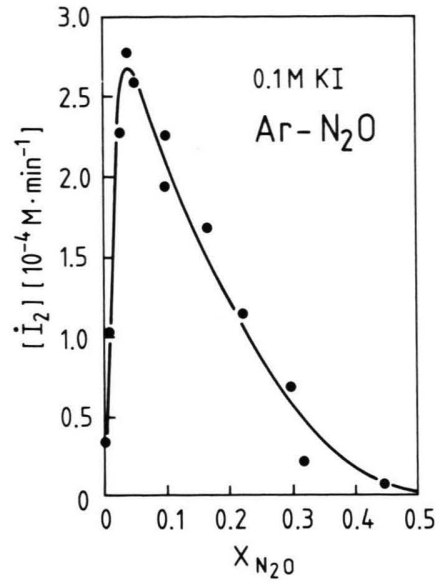

Fig. 5. Rate of $\mathrm{I}_{2}$ formation as a function of the mole fraction of $\mathrm{N}_{2} \mathrm{O}$. Sonication of a $0.1 \mathrm{M}$ KI solution under an $\mathrm{Ar}-\mathrm{N}_{2} \mathrm{O}$ atmosphere.

A promotion of other oxidations was also detected. In an $0.1 \mathrm{M} \mathrm{NaNO}_{2}$ solution, nitrate was formed at a five times greater rate when $4 \%$ of nitrous oxide was present in the argon atmosphere. In a $0.01 \mathrm{M}$ propanol-2 solution acetone was formed at a 2.5 times greater rate. It was also found that $\mathrm{H}_{2} \mathrm{O}_{2}$ is produced in water at twice the rate observed in the absence of nitrous oxide. (In this experiment, $5 \cdot 10^{-4} \mathrm{NaN}_{3}$ was present in the water in order to destroy nitrite which disturbs the detection of $\mathrm{H}_{2} \mathrm{O}_{2}$ with titanyl sulfate.)

Table I shows the various products formed in the sonication of water under an argon-nitrous oxide atmosphere $\left(\mathrm{X}_{\mathrm{N}_{2} \mathrm{O}}=0.04\right)$. The last column of the table contains the yields observed for the irradiation of water under pure argon. Nitrogen, nitrite and nitrate are produced with comparable yields. The yield of $\mathrm{H}_{2}$ is strongly decreased in the presence of nitrous

Tab. I. Product yields in the sonication of water under an atmosphere of argon-nitrous oxide $\left(\mathrm{X}_{\mathrm{N}_{2} \mathrm{O}}=0.04\right)$ and under pure argon. Irradiation time: $10 \mathrm{~min}$.

\begin{tabular}{lll}
\hline Product & $\begin{array}{l}\mathrm{Ar}-\mathrm{N}_{2} \mathrm{O} \text { Mixture } \\
\left(\mathrm{X}_{\mathrm{N}_{2} \mathrm{O}}=0.04\right)\end{array}$ & Pure argon \\
\hline Nitrogen & $1.2 \times 10^{-3} \mathrm{M}$ & - \\
Oxygen & $2.9 \times 10^{-4} \mathrm{M}$ & $2.6 \times 10^{-5} \mathrm{M}$ \\
Hydrogen & $3.0 \times 10^{-5} \mathrm{M}$ & $3.6 \times 10^{-4} \mathrm{M}$ \\
Hydrogen peroxide & $6.0 \times 10^{-4} \mathrm{M}$ & $3.2 \times 10^{-4} \mathrm{M}$ \\
Ammonia & $7.0 \times 10^{-5} \mathrm{M}$ & - \\
Nitrite anion & $9.4 \times 10^{-4} \mathrm{M}$ & - \\
Nitrate anion & $6.8 \times 10^{-4} \mathrm{M}$ & - \\
\hline
\end{tabular}


oxide. This shows that $\mathrm{N}_{2} \mathrm{O}$ is partly reduced. In fact, a small yield of ammonia was observed.

It has been known for a long time that $\mathrm{NO}_{2}{ }^{-}$and $\mathrm{NO}_{3}{ }^{-}$are formed in irradiated water in the presence of air $[13,14]$. In the solutions containing $\mathrm{N}_{2} \mathrm{O}-\mathrm{Ar}$, the yields of these products are about ten times greater than in aerated water. Large yields were also observed when water was irradiated in the presence of both $\mathrm{N}_{2} \mathrm{O}$ and $\mathrm{O}_{2}$. Fig. 6 shows the yields of $\mathrm{NO}_{2}^{-}$ plus $\mathrm{NO}_{3}{ }^{-}$as a function of the mole fraction of $\mathrm{N}_{2} \mathrm{O}$ in the $\mathrm{N}_{2} \mathrm{O}-\mathrm{O}_{2}$ gas mixture. The shape of the curve in Fig. 6 is similar to that in Fig. 5.

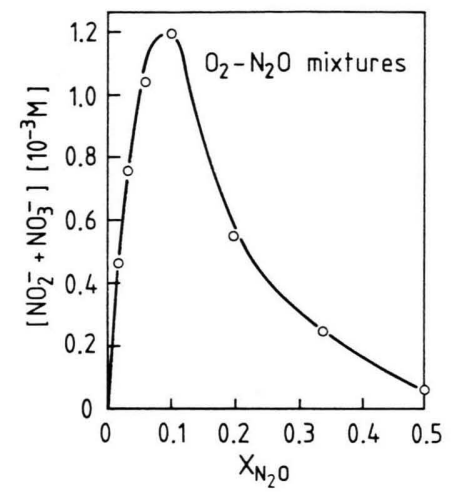

Fig. 6. Yield of $\mathrm{NO}_{2}{ }^{-}$plus $\mathrm{NO}_{3}{ }^{-}$as a function of the mole fraction of $\mathrm{N}_{2} \mathrm{O}$. Irradiation of water under an atmosphere of $\mathrm{N}_{2} \mathrm{O}$ and $\mathrm{O}_{2}$.

\section{Sonolysis of solutions containing $\mathrm{CH}_{4}$}

Fig. 7 shows the yields of various products as function of the mole fraction of methane in the argon atmosphere. It is seen that the $\mathrm{H}_{2} \mathrm{O}_{2}$ yield drastically decreases. This indicates a strong interference of methane with the sonolysis of water. The $\mathrm{H}_{2}$ yield strongly increases and decreases again after having reached a maximum at $\mathrm{X}_{\mathrm{CH}_{4}}=0.08$. The oxidation products of methane were compounds which contained oxygen, such as $\mathrm{CO}, \mathrm{CO}_{2}$, and $\mathrm{CH}_{2} \mathrm{O}$, and compounds without oxygen, such as $\mathrm{C}_{2} \mathrm{H}_{4}, \mathrm{C}_{2} \mathrm{H}_{6}$ and various $\mathrm{C}_{3}$ - and $\mathrm{C}_{4}$-compounds. In Fig. 7 , the yields of $\mathrm{CO}$ plus $\mathrm{CO}_{2}$ and of $\mathrm{C}_{2} \mathrm{H}_{6}+\mathrm{C}_{2} \mathrm{H}_{4}$ are also plotted. The concentration ratio $\mathrm{CO}: \mathrm{CO}_{2}: \mathrm{CH}_{2} \mathrm{O}$ was 1:0.13:0.02. The ratio of concentration of $\mathrm{C}_{2} \mathrm{H}_{6}: \mathrm{C}_{2} \mathrm{H}_{4}$ was 2 at $\mathrm{X}_{\mathrm{CH}_{4}}=0.05$, and 1.3 at $\mathrm{X}_{\mathrm{CH}_{4}}=$ 0.1 , and 0.7 at $\mathrm{X}_{\mathrm{CH}_{4}}=0.2$, and 0.2 at $\mathrm{X}_{\mathrm{CH}_{4}}=0.5$. These yield $v s$. concentration curves also have maxi-

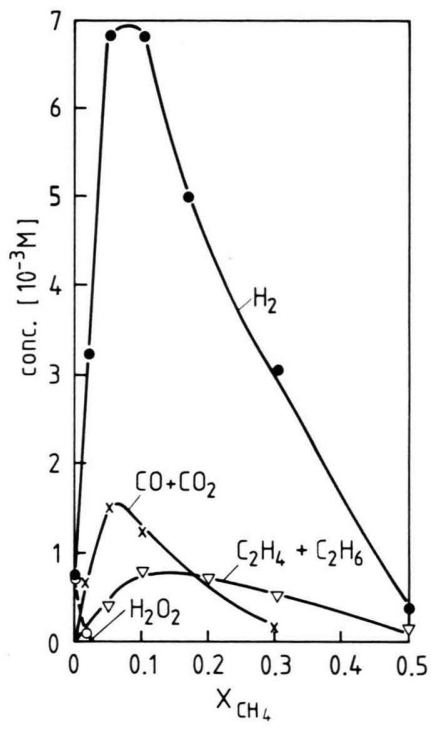

Fig. 7. Irradiation of water under argon-methane mixtures. Concentration of products as a function of the mole fraction of $\mathrm{CH}_{4}$.

ma at $\mathrm{X}_{\mathrm{CH}_{4}}=0.08$ for $\mathrm{CO}+\mathrm{CO}_{2}$ and at $\mathrm{X}_{\mathrm{CH}_{4}}=0.13$ for $\mathrm{C}_{2} \mathrm{H}_{6}+\mathrm{C}_{2} \mathrm{H}_{4}$. The total yield of $\mathrm{C}_{3}$ and $\mathrm{C}_{4}$ products (propane and propene, butane and various butenes) was about equal to the yield of ethane plus ethene.

\section{Discussion}

\section{Shape of yield vs. concentration curves}

When aqueous solutions are irradiated with ultrasonic waves under an argon atmosphere which contains small amounts of $\mathrm{CO}_{2}, \mathrm{~N}_{2} \mathrm{O}$, or $\mathrm{CH}_{4}$, the yields of the products often depend on the concentration of the added gas as illustrated by Figs. 1, 3, 5, and 7. At small concentrations, the yield increases until a maximum value is reached, and it decreases at larger concentrations. A similar behaviour was observed in the experiment of Fig. 6 where sonication was carried out under an oxygen atmosphere containing various amonts of $\mathrm{N}_{2} \mathrm{O}$.

The increase in yield at small concentrations of the added polyatomic gas results from the fact that the gas is a reactant. It may react with the $\mathrm{H}$ and $\mathrm{OH}$ radicals from the sonolysis of water or it is directly decomposed at the high temperatures existing in the collapsing gas bubbles. The decrease in yield at larger concentrations of the polyatomic gas is attri- 
buted to the increase in the heat capacity of the gas mixture. The temperature reached in the adiabatic compression phase of a bubble is

$$
\mathrm{T}=\frac{\mathrm{T}_{\mathrm{o}} \cdot \mathrm{P}_{\mathrm{a}}(\gamma-1)}{\mathrm{Q}}
$$

where $T_{o}$ is the ambient temperature, $P_{a}$ the acoustic pressure at the initiation of collapse, $\gamma$ the ratio of specific heats of the gas mixture, and $\mathrm{Q}$ is the gas pressure in the bubble at the initiation of collapse [4]. For argon, $(\gamma-1)$ is 0.67 , and for $\mathrm{O}_{2}$ it is 0.30 . In the cases of $\mathrm{CO}_{2}, \mathrm{~N}_{2} \mathrm{O}$ and $\mathrm{CH}_{4}(\gamma-1)$ has the respective values $0.17,0.17$, and 0.11 (at $1000{ }^{\circ} \mathrm{C}$ ).

The maxima in the yield $v s$. concentration curves lie at very low concentrations in the cases of carbon dioxide (Figs. 1 and 3) and nitrous oxide (Fig. 5). In these gas mixtures, the deteriorating effect of the polyatomic gas already becomes noticeable, although the ratio $\gamma$ is not much smaller than in pure argon. The yield $v s$. concentration curves behave as if the mole fraction of the polyatomic gas in the chemically active gas bubbles was much larger than in the gas atmosphere under which the ultrasonic irradiation was carried out. $\mathrm{CO}_{2}$ and $\mathrm{N}_{2} \mathrm{O}$ are much more soluble in water than is argon. In the extreme case of non-equilibrium between the gas bubbles and the liquid phase, the composition of the bubbles would be the same as that of the gas solution, i.e. the more soluble gas would be enriched in the gas bubbles as compared to the composition of the gas atmosphere above the liquid. Such a composition of the tiny gas bubbles may indeed be achieved because of the kinetics of their formation. The void which is first produced in the liquid will acquire all the gas molecules which are present within a certain distance. Equilibration will take place much later after the bubble has moved into an undisturbed region of the solution. The time for this equilibration may be longer than the time during which the tiny gas bubbles exert their chemical effects.

The solubilities of argon and methane are not much different (Ar: $2 \times 10^{-3} \mathrm{M} ; \mathrm{CH}_{4}: 1.5 \times 10^{-3} \mathrm{M}$ ). The composition of the gas bubbles and the atmosphere of an $\mathrm{Ar}-\mathrm{CH}_{4}$-mixture is expected to be almost the same. This explains why the maxima of the yield vs. $\mathrm{CH}_{4}$-concentration curve in Fig. 7 lie at a higher concentration than the maxima in Fig. 1 $\left(\mathrm{Ar}-\mathrm{CO}_{2}\right)$ and Fig. $5\left(\mathrm{Ar}-\mathrm{N}_{2} \mathrm{O}\right)$, and that the decrease in yield at higher concentrations of the polyatomic gas is not so rapid as in the cases of the
$\mathrm{Ar}-\mathrm{CO}_{2}$ and $\mathrm{Ar}-\mathrm{N}_{2} \mathrm{O}$ mixtures. The same argument applies to $\mathrm{Ar}-\mathrm{H}_{2}$ mixtures, where it has previously been found that maximum yield of reduction processes is observed at a rather large fraction of $\mathrm{H}_{2}$ $\left(\mathrm{X}_{\mathrm{H}_{2}}=0.20\right)$ as the gas with the lower value of $(\gamma-1)$. Hydrogen is less soluble than argon $\left(\mathrm{H}_{2}: 8 \times 10^{-4} \mathrm{M}\right)$, i.e. the gas bubbles may contain even less $\mathrm{H}_{2}$ than the atmosphere under which the irradiation occurs [15].

\section{Sonolysis in the presence of $\mathrm{CO}_{2}$}

The decrease in the $\mathrm{H}_{2}$ yield upon addition of very small amounts of $\mathrm{CO}_{2}$ to the argon atmosphere (Fig. 1) is explained by the scavenging of $\mathrm{H}$ atoms from the sonolysis of water:

$$
\mathrm{H}_{2} \mathrm{O} \rightarrow \mathrm{H}+\mathrm{OH}
$$

in the absence of $\mathrm{CO}_{2}$ :

$$
\begin{aligned}
& 2 \mathrm{H} \rightarrow \mathrm{H}_{2} \\
& 2 \mathrm{OH} \rightarrow \mathrm{H}_{2} \mathrm{O}_{2}
\end{aligned}
$$

in the presence of $\mathrm{CO}_{2}$ :

$$
\mathrm{CO}_{2}+\mathrm{H} \rightarrow \mathrm{CO}_{2} \mathrm{H}
$$

The final products of this scavenging action of $\mathrm{CO}_{2}$ are $\mathrm{CO}$ and small amounts of $\mathrm{HCOOH}$. At the same time, the hydrogen peroxide yield is increased (Fig. 1). This may be understood in terms of the recombination reaction

$$
\mathrm{H}+\mathrm{OH} \rightarrow \mathrm{H}_{2} \mathrm{O}
$$

which takes place in the absence of the scavenger. As $\mathrm{H}$ atoms are scavenged by $\mathrm{CO}_{2}$, more $\mathrm{OH}$ radicals escape recombination and can form $\mathrm{H}_{2} \mathrm{O}_{2}$. The mechanism of eqs. $(2-6)$ means that the sonolyses of water and carbon dioxide are strongly linked to each other. The maximum in the yield of $\mathrm{H}_{2} \mathrm{O}_{2}$ occurs at a mole fraction of $\mathrm{CO}_{2}$ of 0.005 which is smaller than that of the $\mathrm{CO}$ yield $\left(\mathrm{X}_{\mathrm{CO}_{2}}=0.01\right)$. We explain this effect by postulating a second kind of formation of $\mathrm{CO}$ as $\mathrm{CO}_{2}$ is directly decomposed by the high temperatures in the collapsing gas bubbles:

$$
\mathrm{CO}_{2} \rightarrow \mathrm{CO}+\mathrm{O}
$$

The oxygen atoms formed may either form oxygen

$$
\mathrm{O} \rightarrow 1 / 2 \mathrm{O}_{2}
$$

or react with hydrogen atoms from the sonolysis of water

$$
2 \mathrm{H}+\mathrm{O} \rightarrow \mathrm{H}_{2} \mathrm{O}
$$


As only very small oxygen yields were found, reaction 9 must be the main process of the disappearance of intermediate oxygen atoms. At larger $\mathrm{CO}_{2}$ concentrations in Fig. 1, all the yields decrease as the temperature reached in the collapsing gas bubbles becomes lower. This effect of $\mathrm{CO}_{2}$ can also be recognized from the yields $v s$. concentration curve for the oxidation of iodide (Fig. 2). The oxidation of $\mathrm{I}^{-}$is attributed to the reaction

$$
\mathrm{OH}+\mathrm{I}^{-} \rightarrow \mathrm{OH}^{-}+\mathrm{I}
$$

As $\mathrm{I}^{-}$has not a substantial vapor pressure one must assume that this process occurs in the liquid phase, i.e. $\mathrm{OH}$ radicals formed in the collapse of the gas bubles must have reached the liquid phase before combining to $\mathrm{H}_{2} \mathrm{O}_{2}$ (eq. (4)) in the gas bubble. However, it seems difficult to distinguish exactly between gas phase and liquid phase reactions at the short times in which the gas bubbles collapse under a high pressure.

In the presence of $0.05 \mathrm{M}$ ethanol and $\mathrm{CO}_{2}$, acetic and lactic acid are produced in addition to formic acid (Fig. 3). In the absence of $\mathrm{CO}_{2}$, practically no $\mathrm{CH}_{3} \mathrm{COOH}$ was found after the irradiation. It has to be concluded that the two organic acids are combination products of the sonolyses of $\mathrm{CO}_{2}$ and ethanol. We already have postulated the $\mathrm{CO}_{2} \mathrm{H}$ radical as an intermediate of the sonolysis of $\mathrm{CO}_{2}$ (eq. (5)). The combination with $\mathrm{CH}_{3}$ and $\mathrm{CH}_{3} \mathrm{CHOH}$ radicals from the sonolysis of ethanol would yield the two carboxylic acids. Ethanol undergoes a strong sonolysis as can be recognized from the yields of aldehydes (Fig. 4). In the presence of $\mathrm{CO}_{2}$, the yield is practically unchanged at low $\mathrm{CO}_{2}$ concentrations, i.e. the formation of the acids is only a minor side reaction of the sonolysis of ethanol.

\section{Sonolysis in the presence of $\mathrm{N}_{2} \mathrm{O}$}

Nitrous oxide is known to serve as an oxidizing agent in combustions by delivering the necessary oxygen. In the ultrasonic irradiation of aqueous solutions containing small amounts of $\mathrm{N}_{2} \mathrm{O}$ in addition to argon, a similar effect seems to take place, the delivered oxygen being in a particularly reactive state, possibly in the form of oxygen atoms from the thermal dissociation reaction

$$
\mathrm{N}_{2} \mathrm{O} \rightarrow \mathrm{N}_{2}+\mathrm{O}
$$

The decrease in the hydrogen yield in the presence of $\mathrm{N}_{2} \mathrm{O}$ indicates that $\mathrm{N}_{2} \mathrm{O}$ interferes with the sonolysis of water, probably by reacting with intermediate $\mathrm{H}$ atoms:

$$
\mathrm{N}_{2} \mathrm{O}+\mathrm{H} \rightarrow \mathrm{N}_{2}+\mathrm{OH}
$$

The $\mathrm{O}$ atoms and $\mathrm{OH}$ radicals formed in reactions 11 and 12 may then oxidize iodide (Fig. 5) or other solutes such as nitrate or propanol-2. In all these solutions, the rate of oxidation is markedly increased in the presence of $4 \% \mathrm{~N}_{2} \mathrm{O}$ in the argon atmosphere. It is not possible at the present time to decide which of the two reactions 11 and 12 is more important for the enhancement of the oxidation yields.

The sonolysis of $\mathrm{N}_{2} \mathrm{O}$ in aqueous solution is more complex than would be expected from the occurrence of reactions 11 and 12 . The fact that nitrate and nitrite were also formed besides $\mathrm{N}_{2}$ and that small amounts of ammonia were detected shows that $\mathrm{N}_{2} \mathrm{O}$ decomposes in a complex manner. The formation of these products can only be understood by a strong linkage between the sonolyses of $\mathrm{N}_{2} \mathrm{O}$ and water. The relatively large yields of $\mathrm{NO}_{2}{ }^{-}$and $\mathrm{NO}_{3}{ }^{-}$(Fig. 6) in $\mathrm{N}_{2} \mathrm{O}$ solutions containing $\mathrm{O}_{2}$ as the supporting gas may be taken as indication that the oxygen also acts chemically on $\mathrm{N}_{2} \mathrm{O}$, possibly via the formation of $\mathrm{O}$ atoms and subsequent reactions of the $\mathrm{O}$ atoms with $\mathrm{N}_{2} \mathrm{O}$.

\section{Sonolysis in the presence of $\mathrm{CH}_{4}$}

Methane can be expected to react with both $\mathrm{OH}$ and $\mathrm{H}$ radicals from the sonolysis of water:

$$
\begin{aligned}
& \mathrm{CH}_{4}+\mathrm{OH} \rightarrow \mathrm{CH}_{3}+\mathrm{H}_{2} \mathrm{O} \\
& \mathrm{CH}_{4}+\mathrm{H} \rightarrow \mathrm{CH}_{3}+\mathrm{H}_{2}
\end{aligned}
$$

The drastic decrease in the $\mathrm{H}_{2} \mathrm{O}_{2}$ yield at very small methane concentrations is understood in this way (Fig. 7). The increase in the $\mathrm{H}_{2}$ yield, however, was much stronger than the decrease in the $\mathrm{H}_{2} \mathrm{O}_{2}$ yield. This again can be understood in terms of the recombination reaction 6 which strongly limits the yields of $\mathrm{H}_{2}$ and $\mathrm{H}_{2} \mathrm{O}_{2}$ in the sonication of water under pure argon. In the presence of methane this recombination reaction is suppressed. In addition, methane molecules may be decomposed thermally

$$
\mathrm{CH}_{4} \rightarrow \mathrm{CH}_{3}+\mathrm{H}
$$

The $\mathrm{H}$ atoms formed in this way would also contribute to the $\mathrm{H}_{2}$ yield. The formation of ethane and ethylene is simply explained in terms of the methyl radical reactions 


$$
2 \mathrm{CH}_{3} \nearrow^{\mathrm{C}_{2} \mathrm{H}_{2}}{ }_{\mathrm{C}_{2} \mathrm{H}_{4}+\mathrm{H}_{2}}^{\searrow_{\mathrm{C}_{2} \mathrm{H}_{5}+\mathrm{H}}}
$$

which are known to occur at high temperatures [16]. In considering reactions of $\mathrm{H}$ and $\mathrm{OH}$, one should not forget that the reaction

$$
\mathrm{H}+\mathrm{H}_{2} \mathrm{O} \rightarrow \mathrm{H}_{2}+\mathrm{OH}
$$

can take place at high temperatures, i.e. the number of $\mathrm{H}$ atoms and $\mathrm{OH}$ radicals which can react with a scavenger must not necessarily correspond to the stoichiometry of radical formation in reaction 2 $[16,17]$.

Reactions 13-18 cannot explain the formation of the oxygen containing products, i.e. mainly $\mathrm{CO}$ (Fig. 7). The oxygen must originate from water, the overall reaction leading to $\mathrm{CO}$ being

$$
\mathrm{CH}_{4}+\mathrm{H}_{2} \mathrm{O} \rightarrow \mathrm{CO}+3 \mathrm{H}_{2}
$$

The yield of the oxygen containing products at $\mathrm{X}_{\mathrm{CH}_{4}}=$ 0.1 was about twice the yield of $\mathrm{H}_{2} \mathrm{O}_{2}$ in the absence of methane. The number of water molecules decomposed therefore was the same in the presence and absence of methane. However, as we have to postulate reaction 13 , many water molecules must have been re-formed, or, in other words, many more water molecules must initially have been decomposed than is calculated from the yield of the final products containing oxygen. Once more, the back reaction 6 has to be postulated.

Reaction 20 must occur through a mechanism in which a methane molecule is attacked by many $\mathrm{OH}$ radicals (the alternative option would be a reaction of the $\mathrm{CH}_{3}$ radical with water leading to the formation of a $\mathrm{C}-\mathrm{O}$ bond. Such a reaction has never been observed in free radical chemistry). Multiple radical attack on molecules would be possible, if the local concentration of radicals in the gas bubble is so high that radical-radical reactions are as abundant or even more preferred than reactions of the radicals with methane molecules which do not lead to the formation of $\mathrm{C}-\mathrm{O}$ bonds. For example, $\mathrm{CH}_{3}$ could react with $\mathrm{OH}$ to yield $\mathrm{CH}_{2} \mathrm{OH}+\mathrm{H}$, followed by $\mathrm{CH}_{2} \mathrm{OH}+\mathrm{OH} \rightarrow \mathrm{CH}(\mathrm{OH})_{2}+\mathrm{H} \stackrel{-\mathrm{H}_{2} \mathrm{O}}{\longrightarrow} \mathrm{CH}=\mathrm{O}$, followed by $\mathrm{CH}=\mathrm{O}+\mathrm{OH}(\mathrm{H}) \rightarrow \mathrm{CO}+\mathrm{H}_{2} \mathrm{O}\left(\mathrm{H}_{2}\right)$.

The formation of $\mathrm{C}_{3}$ - and $\mathrm{C}_{4}$-hydrocarbons could occur via the ethyl radicals formed in reaction 18 or via the radical attack on ethane and ethylene formed in reactions 16 and 17. It is interesting to note that the formation of the higher hydrocarbons besides $\mathrm{CO}$ and $\mathrm{CO}_{2}$ is typical for methane flames which are deficient in oxygen [16].

\section{Final Conclusions}

The sono-chemistry occurring in aqueous solutions in an argon atmosphere to which small amounts of a polyatomic gas are added is characterized by a strong linkage between the sonolyses of water and the added gas. The latter can act as a scavenger for free radicals formed in the sonolysis of water. It may also act via direct thermal decomposition, and finally may inhibit chemical reactions as the heat capacity of the gas in the bubbles is increased. The latter effect can occur at only a few percent of a polyatomic gas having a solubility substantially greater than argon. This is explained by the fact that gas bubbles are not in Henry's equilibrium with the surrounding aqueous gas solution, an effect, which has not yet been considered in the discussions on chemical and physical effects of cavitation.

The free radical reactions which have to be postulated are typical for the reactions which are known to occur in flames. In this respect, sonolytic reactions differ strongly from photolytic and radiolytic processes in liquids. It is also recognized that the local radical concentrations are so high that radical-radical reactions occur at a rate comparable to that of radical-molecule reactions. This allows molecules of the added polyatomic gas to be attacked by several radicals. The sonolytic reactions resemble flame reactions also in this regard.

The author gratefully acknowledges the assistance of Mrs. H. Pohl and Mrs. S. Podgurski in the analytical work.
[1] I. E. El'Piner, Ultrasound, Physical, Chemical and Biological Effects, Consultants Bureau, New York 1964; many references therein.
[2] A. Weissler, in Encyclopedia of Chemical Technology, edited by R. E. Kirk and D. F. Othmer, Wiley Interscience, New York, 3rd edition 15, 773 (1981); many references therein. 
[3] M. E. Fitzgerald, V. Griffing, and J. Sullivan, J. Chem. Phys. 25, 926 (1956).

[4] B. E. Noltingk and E. A. Neppiras, Proc. Phys. Soc. B 63, 674 (1950).

[5] H. G. Flynn, J. Acoust. Soc. Am. 72, 1926 (1982).

[6] P. Günther, U. Zeil, U. Grisar, and E. Heim, Z. Elektrochemie, 61, 188 (1957).

[7] C. Sehgal, R. G. Sutherland, and R. E. Verrall, J. Phys. Chem. 84, 388 (1980).

[8] A. Henglein and R. Schulz, Z. Naturforsch. 7b, 484 (1952).

[9] K. Makino, M. M. Mossoba, and P. Riesz, J. Phys. Chem. 87, 1369 (1983).

[10] A. J. Carmichael, M. M. Mossoba, P. Riesz, and C. L.
Christman, presented at the 32nd meeting of the Radiation Research Society, Orlando, Fl., March 1984.

[11] A. Henglein and R. Schulz, Z. Naturforsch. 8b, 277 (1953).

[12] A. Henglein, M. Gutiérrez, and Ch.-H. Fischer, Ber. Bunsenges. Phys. Chem. 88, 170 (1984).

[13] H. Beuthe, Z. Phys. Chem. 163 A, 161 (1933).

[14] I. G. Polotzki, J. gen. Chem. (USSR) 17, 649 (1947).

[15] A. Henglein, Naturwissenschaften 43, 277 (1956); 44, 179 (1957).

[16] J. Warnatz, Ber. Bunsenges. Phys. Chem. 87, 1008 (1983); further references cited therein.

[17] M. Anbar and I. Pecht, J. Phys. Chem. 71, 1246 (1967). 